\title{
Investigating the presence of mold in wood treated with chlorophenol
}

\author{
Olle Ekberg ${ }^{1}$, Johnny C. Lorentzen ${ }^{2}$, and Lars-Erik Harderup ${ }^{1}$ \\ ${ }^{1}$ Division of Building Physics, Lund University, Lund, Sweden \\ ${ }^{2}$ Institute of Environmental Medicine, Karolinska Institutet, Stockholm, Sweden.
}

\begin{abstract}
A common moisture-related problem in Sweden and other countries, is mold odor indoors. The general perception is that mold odor indicates hazardous hidden mold. However, some grey literature studies indicate that the source of mold odor might not be substantial amounts of mold, but rather chloroanisoles (CAs) which are biomethylated from chlorophenols (CPs) in moist conditions. Products containing CPs were commonly used world-wide as wood preservatives in the 1960-70s and problems with indoor mold odor have been reported in buildings where such products have been used. In Sweden, one of the main uses of CPs in buildings was in wooden constructions exposed to big moisture loads, such as sill plates and crawl space ceilings. Here we aimed to determine the potential presence and level of mold growth on wood treated with CPs in one school building with reported odor problems built in the stated time period. Odorous wooden samples were taken and analyzed for mold growth. No mold was detected by the naked eye, but some growth was seen using a microscope. We presently investigate more schools and samples, but so far our results question that mold odor depends on substantial amounts of mold.
\end{abstract}

\section{Introduction}

A common moisture-related problem in Sweden, as well as other Nordic countries, is mold odor indoors. There have been reports and other studies that indicate that the source of mold odor might not always be actual mold but rather something else [1][2]. One theory is that the source for mold odor in these buildings are chloroanisoles (CAs) which are biomethylated from chlorophenols (CPs) [3][4]. CPs in themselves are not very odorous but the CAs have very low odor thresholds [2][5]. The odor of CAs has been mistaken for mold odor due to the suspicion for mold growth in the constructions exposed to high moisture loads, such as sill plates. Malodor from pressurepreservative treated (PPT) sill plates have been previously investigated by the Swedish Wood Preservation Institute and correlation between mold growth and malodor was not found [1]. The investigation did show a connection between malodor and moisture content in the sill plates.

In Sweden, chlorophenols were used in products for wood preservation from 1955 until 1978 when products containing CPs were retracted. [6] The wood preservatives were applied in different ways, depending on what the final use would be for the treated wood. It could be either through pressure preservation, dipping the wood or painting the constructed surfaces [3].

During the time that CPs were used, the Swedish building regulations changed and started to ordinate chemical protection for wood instead of other means of protection, such as better design or moisture barriers. The wood preservatives were demanded for constructions that could be vulnerable to rot, such as sill plates, beams and ceilings in crawl spaces. The wood preservatives were intended to prevent wood decay fungi and they were assumed to also prevent mold growth. [4][7][8]

In the winter of 2006, a large-scale national study was conducted on the condition of approximately 1800 Swedish buildings. Through building inspections, it was found that about $30 \%$ of the buildings had issues with either mold growth or mold odor. The study categorized mold growth as a sign of moisture damage if either mold growth visible to the naked eye could be found or if mold odor was noticed, even when no visible mold was reported [9]. Mold odor was found in approximately $10 \%$ of all single-family houses and non-residential buildings and were most common for houses from 1960s-70s, i.e. the time period when CPs were used in buildings.

The aim of this study is to investigate the potential presence and level of mold growth on preserved wood from odorous constructions treated with CPs. The degree of mold growth is assessed both by the naked eye as well as using a microscope.

\section{Method}

Three different elementary schools were chosen for investigation but in this paper we present results obtained so far for one of these schools.

The investigated objects are all in the city of Gothenburg in Sweden (57०42'35.1"N 11 $\left.{ }^{\circ} 58^{\prime} 28.8^{\prime \prime} \mathrm{E}\right)$. The samples were taken at the end of October 2019. The climate is temperate with a yearly mean temperature of $7.6^{\circ} \mathrm{C}$ and yearly mean precipitation of $772 \mathrm{~mm}$. [10]

\footnotetext{
* Corresponding author: olle.ekberg@,byggtek.lth.se
} 


\subsection{Investigation profile}

The three schools were chosen because they fit the desired profile determined together with an indoor environment specialist that works for the company that is managing the buildings. To fit the profile, the building had to fulfill four demands. Firstly, being constructed during the Swedish building boom in the 1960s-70s and built according to the building regulations of that time. This means that the buildings were most likely built with ordinated use of wood preservatives in the wooden construction parts exposed to high moisture loads, such as sill plates and crawl space ceilings. Secondly, that the building had reported problems with indoor malodor. Thirdly, accessible construction details with suspected use of wood preservatives to take samples from. Fourthly, that the building had undergone some form of renovation or measure to remove the indoor malodor. Other things that were considered were the available documentation of the building in the form of blueprints, technical descriptions, reports from consultants, lab analyses, correspondence between the on-site staff and the real estate manager etc.

\subsection{Investigated object}

The object presented in this paper fits the desired profile. The school is a wooden frame building that was built in 1969 and has a crawl space underneath the building and crawl space walls made out of hollow concrete blocks with smoothing concrete on top.

Inspection of the blueprints and technical descriptions for the school show that wood preservatives were in fact ordinated for use in the sill plates. The image in Fig. 1 show one of the blueprint details of the crawl space wall and the PPT sill plate.

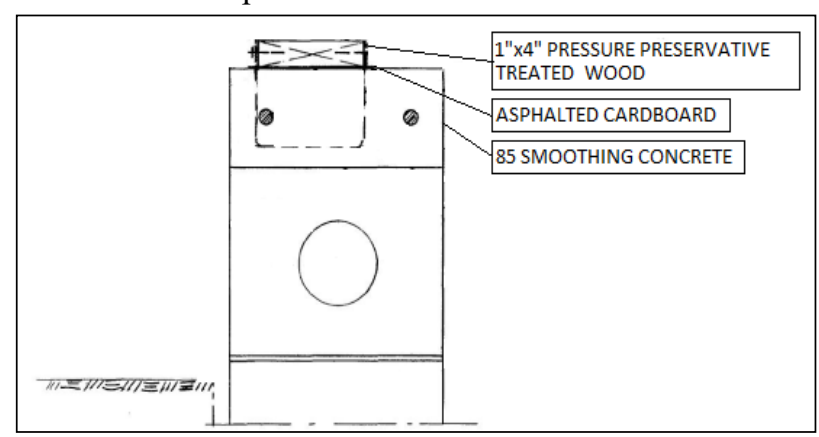

Fig. 1: Construction detail of the crawl space wall with ordinated use of wood preservatives. The text is translated from the original Swedish.

Correspondence between the property manager and the personnel working in the schools with reported problems of poor indoor air quality and mold odor indoors show that the children were reported to "smell like school" by the parents. This correspondence led to a malodor investigation in 2016 ordered by the property manager and performed by consultants. The investigation highlighted various problems with the crawl space, mainly pointing out a strong chemical odor, suspecting the source to be from wood preservatives due to the brown coloration of the crawl space ceiling. A sample from the crawl space ceiling was taken and sent for analysis, which indicated positive results for CPs and CAs. The solution suggested by the consultants was to seal off the crawl space, preventing air from the crawl space to leak into the indoor air.

The crawl space was originally built as an open ventilated crawl space but the crawl space vents together with leaky construction details in the crawl space ceiling has been sealed since the investigation and the crawl space has had mechanical extract ventilation installed. The intention was to create a negative pressure in the crawl space compared to the indoor environment to prevent malodor from leaking into the indoor air. The exhaust air from the crawl space air vent is redirected up above the roof to prevent malodor near the surrounding area.

\subsection{Sample collection and analysis}

For this study, we have taken material samples to analyze possible mold growth on the construction details. Samples were taken from several points in the crawl space and in this paper we present a few of the samples from the north facing facade.

The construction details of interest were the sill plates and the crawl space ceiling. Measuring points were chosen in both the north and south facing facades as well as a reference point in the center part of the building. The samples collected were $3 \mathrm{~cm}$ wide and $5-10 \mathrm{~cm}$ long wooden slivers carved from the sill plates or the crawl space ceiling. The chisel used to carve the samples was cleaned with denatured alcohol between each collection to prevent contamination. Care was taken to not touch the surfaces of the samples. Larger samples of the sill plates were not possible to carve out due to the narrow space between the crawl space ceiling and the concrete base. The same dimensions of samples were taken from the crawl space ceiling for more equal comparison between the samples. The samples were wrapped in aluminum foil and put in individual polyethylene zip-lock bags which were marked and numbered.

Wireless sensors of type Omnisense S-160 were installed in the sill plates for measuring the ambient temperature and relative humidity as well as the moisture content (wood moisture equivalent) over a longer time period. These sensors combine the temperature and $\mathrm{RH}$ sensor together with a pin type (resistance) moisture meter for the moisture content and are wirelessly monitored. The moisture content sensors were calibrated by the supplier according to the Timbermaster Protimeter Ascale. The sensor adjusts the moisture content according to the current temperature. [11]

The moisture content at the sample point was also measured using a handheld Timbermaster Protimeter moisture content sensor (pin type) with a connected hammer electrode. The calibration of the moisture content sensor was verified using a resistance-calibration plate. It was calibrated according to the Timbermaster Protimeter A-scale.

Microscopic mold growth analysis of the samples has been done by experienced lab personnel at 
Lund University according to the mold index scale (MI) by Johansson et al. presented in Table 1. The analysis is performed with a microscope at $40 \mathrm{x}$ magnification together with a low-angle light to detect hyaline (transparent) or dematiaceous (brown colored) hyphae. If a sample has an MI rating of 2 or higher, it is considered to have stated mold growth [12].

To determine mold growth at an ocular level, i.e. with the naked eye, a qualified assessment has been made at both the time of the sample collection and later on at an odor neutral site. The assessment has been done looking from above at a fixed distance of $30 \mathrm{~cm}$ with four angled lights surrounding the sample. Photos of the samples were taken at the same distance under the same conditions. An assessment of the odor was also made at this site.

Table 1. Rating scale for the assessment of mold growth at 40x magnification.

\begin{tabular}{ll}
\hline Rating & Description of extent of growth \\
\hline 0 & $\begin{array}{l}\text { No mold growth. } \\
\text { Initial growth, one or a few hyphae and no } \\
\text { conidiophores. }\end{array}$ \\
2 & $\begin{array}{l}\text { Sparse but clearly established growth; often } \\
\text { conidiophores are beginning to develop. }\end{array}$ \\
3 & $\begin{array}{l}\text { Patchy, heavy growth with many well- } \\
\text { developed conidiophores. }\end{array}$ \\
4 & $\begin{array}{l}\text { Heavy growth over more or less the entire } \\
\text { surface }\end{array}$ \\
\hline
\end{tabular}

\subsection{Limitations}

Several objects with previous reported malodor problems were considered for investigation. Due to the need of being able to access the construction details with suspected preservative-treated wood without damaging the interior surfaces together with having general access to the building, a selection had to be made. The three investigated objects were chosen because they were accessible at the time of the investigation.

Another limitation is that all the tested objects are from the same city and not spread out. However, Gothenburg is a city exposed to large amounts of rain and wind compared to other locations in Sweden, which makes for a more non-forgiving climate.

The measured moisture content in the sill plates might be measuring incorrect moisture content due to the salts in the wood preservatives. The resistivity is lowered by the salts and thus displays a higher moisture content. [11][13]

\section{Results}

The samples presented in this paper were gathered from the sill plate and crawl space ceiling in the north facing facade. Fig. 2 show the sample location.

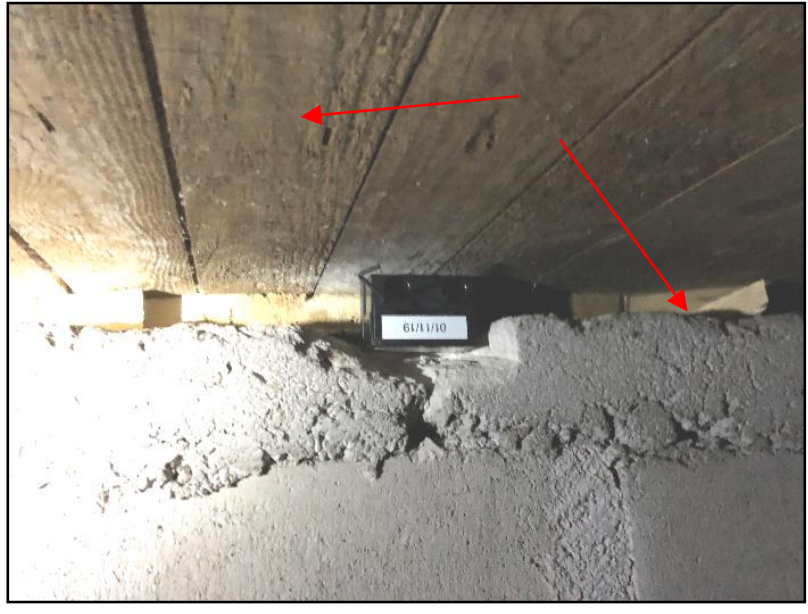

Fig. 2. Sample collection points from the sill plate and the crawl space ceiling in the northern facade. A wireless sensor is installed in the middle.

When inspecting the crawl space for signs of mold growth, no spots of visual growth were found on the sill plates. The crawl space ceiling showed patchy signs of a thin white substance in certain parts, which could be either white mold or efflorescence (salt residue) [14]. The bottom half of the concrete walls were covered in efflorescence.

The crawl space had a distinct smell and when assessing the samples by olfaction at an odor neutral site, the same odor was recognized.

The moisture content measured with the hand held moisture content sensor at the sampling site indicated around $13 \%$ in the sill plate and around $11 \%$ in the crawl space ceiling. The wireless sensor in the sill plate also indicated around $13 \%$ moisture content and the measured surrounding climate in the crawl space was around $13{ }^{\circ} \mathrm{C}$ with a $63 \% \mathrm{RH}$.

Ocular inspection of the samples did not identify mold growth. The sample from the sill plate looks like a fresh piece of wood with a smooth surface of a slightly brownish color compared to the inner parts. An odor is faint but noticeable. The crawl space ceiling sample has a smooth surface of a dark brown color with some darker spots, most likely from the coloration of the wood preservatives. This sample has a much stronger smell compared to the sill plate sample. Sample photos of the ocular assessment can be seen in Fig. 3 and Fig. 5 .

Analysis of the samples using a microscope show that there was some mold growth on the samples. The sill plate sample had MI 2 whereas the crawl space ceiling had MI 3 , using the 0-4 scale. Both samples show hyaline hyphae. The sample photos at $40 \mathrm{x}$ magnification is presented in Fig. 4 and Fig. 6. 


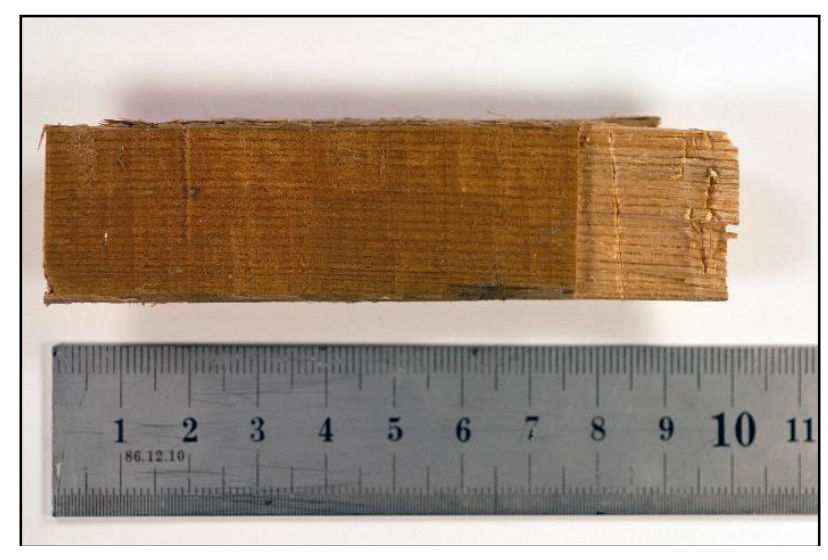

Fig. 3. Sill plate sample. No magnification. MI 2.

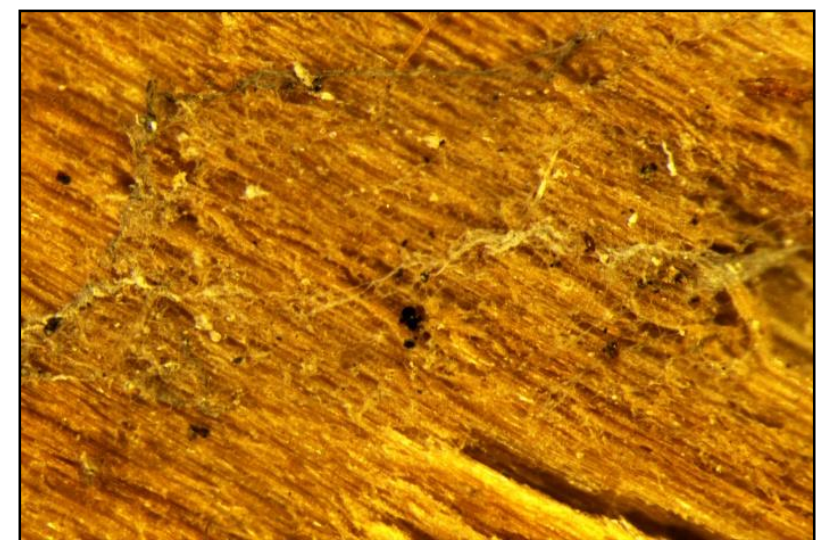

Fig. 4. Sill plate sample. 40x magnification. MI 2.

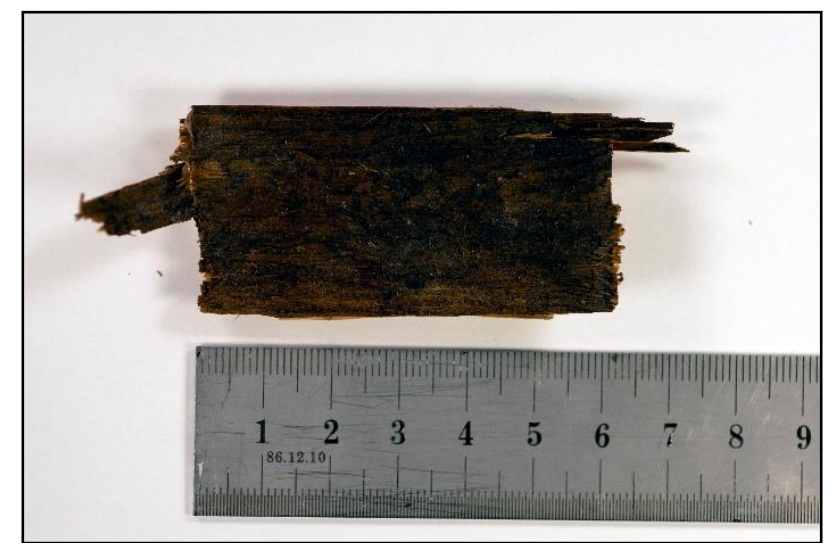

Fig. 5. Crawl space ceiling sample. No magnification. MI3.

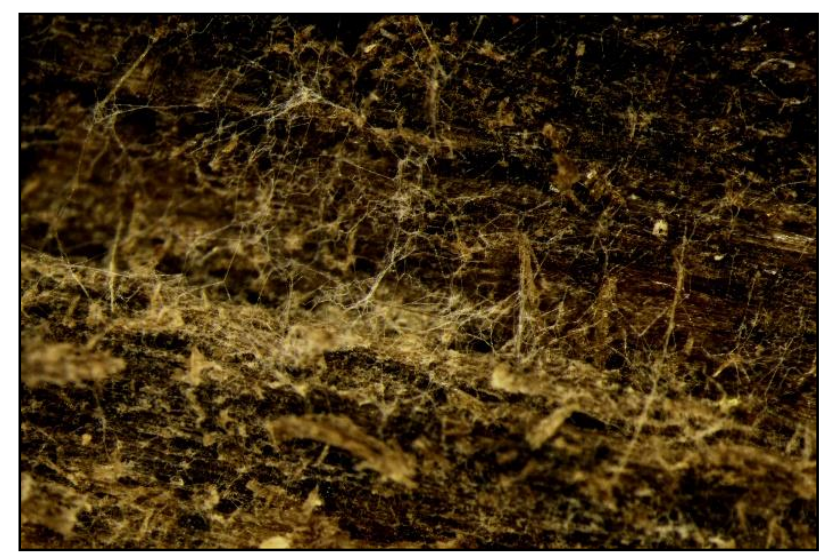

Fig. 6. Crawl space ceiling sample. 40x magnification. MI3.

\section{Analysis and discussion}

The sample of the crawl space ceiling is considerably darker than the sill plate sample, making it harder to distinguish any growth at an ocular level. However, the examining conditions for all samples were the same with equal viewing distance and lighting to make the assessment consistent and comparable.

The microscope analysis both indicated a MI 2 or higher, thus having stated mold growth according to the 0-4 scale [12]. However, the ocular assessment did not identify any clearly visible mold growth but a distinct odor could still be noticed from the samples.

Regarding the national study done in 2006, it is interesting that mold odor alone was considered a sign for moisture damage, assuming the presence of mold growth. This was the stance they took at the time, since they knew that early stages of mold growth doesn't have to be visible with the naked eye to be present [9]. Note that non-visible mold is different to hidden mold, meaning mold inside construction details is hidden and mold visible with a microscope can be non-visible to the naked eye.

The national study did however define what they constituted substantial, visible mold growth on attic ceilings. They defined it as either continuous or patchy growth within a certain area or patchy growth covering the entire ceiling. The total surface area of the mold growth then defined the spread. A noteworthy inclusion was also the degree of mold growth, where they took greater consideration to clearly visible growth compared to barely visible growth. [9]

Looking at our current data from the investigated school, the reported mold odor from the object might not be linked to substantial mold growth by the definition from the national study. This is in line with what the Swedish Wood Preservation Institute has also found on the correlation between odor from wood treated with preservatives and mold growth. [1]

Considering instead the previously suggested association between moisture content in preservative treated wood and odor intensity [1], the mold growth presence may indicate the previous or present moist conditions in the crawl space and the higher moisture content in the wood. As previously stated, when CPs are exposed to moist conditions, microbes produce CAs through biomethylation [3]. The initial mold growth found on the samples might show that the conditions have been favorable for this biomethylation to occur, as the conditions for mold growth are similar.

It has been suggested that if wood have had a high moisture content for a longer period of time before installation or at the time of construction, the permeability of the wood changes [15]. It is possible this is something that has affected the crawl space ceiling when it was painted with wood preservatives at the time of construction. When painted on, the amount of preservatives that gets absorbed by the wood varies depending on how permeable the wood is. [1] There is also a natural variation in permeability between different wood boards. This variation in permeability may explain the patchiness of the white residue found on the crawl space ceiling. It is likely that the moisture content also 
varies between different boards depending on their permeability [16].

The naturally varying RH in the crawl space is also an issue when measuring the moisture content in the wood due to the fact that the measured climate is not fully representative of the yearly crawl space climate. The RH in ventilated crawl spaces is higher in spring and summer compared to fall and winter due to the cold ground cooling the incoming warm, humid air and thus increases the RH [17]. Since the samples were taken at the end of October, it's likely that the measured moisture content and relative humidity is lower than it is in the summer. The measurements taken showed that the climate was relatively dry at the time of sample collection. The wireless sensors installed in the sill plates gives a mean to log the crawl space climate and moisture content in the sill plates over a longer period of time and the results from those measurements will be analyzed further on as we expand on this research.

However, since the investigated crawl space has been sealed off, it is also difficult to fully estimate how much the sealing of the crawl space has impacted the crawl space climate. The measured climate and moisture content at this time does not represent what the climate has been in the crawl space for almost 50 years. Before the sealing, the crawl space was exposed to the outside air with the $\mathrm{RH}$ and temperature in the crawl space depending largely on the outside climate. When the crawl space was sealed off and put under negative pressure compared to the indoor air, it created a different air exchange pattern. There is now a chance for warm indoor air with additional moisture supply to leak into the crawl space where it may cool off and increase the RH. This would make the crawl space climate depend more on the indoor climate. Therefore, the crawl space climate is now presumably warmer but not necessarily dryer compared to how it was before the crawl space vents were sealed. The mold growth found on the samples has most likely grown before the crawl space was sealed off and the crawl space climate was colder.

Considering the age of the building and the state of the crawl space, the wood preservatives used in the crawl space effectively protects the wood against decay fungi but not completely against mold. However, the mold growth is not visible to the naked eye and is not even conspicuous when seen in a microscope. We presently expand on these results but our present results indicate that substantial mold growth is not necessary for odor formation in a crawl space, resulting in annoying indoor odor in the building above the crawl space.

\section{References}

1. E. Nyman, (1994).

2. J. Gunschera, F. Fuhrmann, T. Salthammer, A. Schulze, E. Uhde, M. Uhde, Proc Indoor Air, 2154-2158, (2005).

3. J. C. Lorentzen, S. A. Juran, M. Nilsson, S. Nordin, G. Johanson, Indoor Air, 26, 207-218, (2016)
4. J. C. Lorentzen, G. Johanson, S. A. Juran, L. Ernstgård, and M. J. Olsson, Int. J. Environ. Res. Public Health, 17, (2020).

5. S. T. Lebow, M. Tippie, 4, (2001)

6. Produktkontrollnämnden, 2, (1977)

7. ByggAMA, ByggAMA 1965, 127-129, (1965)

8. Statens Planverk, Svensk Byggnorm 1975, 3, (1975)

9. Boverket, God bebyggd miljö - förslag till nytt delmål för fukt och mögel, 17-45 (2010)

10. Climate-Data.org, [Accessed: 10-Dec-2019].

11. Timbermaster, Calibration tables for wood, (2006)

12. P. Johansson, A. Ekstrand-Tobin, T. Svensson, G. Bok, Int. Biodeterior. Biodegradation, 73, 23-32, (2012)

13. C. Brischke and S. C. Lampen, Eur. J. Wood Wood Prod., 72, 289-292 (2014)

14. E. Catelli, F.-G. Bănică, A. Bănică, Herit Sci, 4, 31 (2016)

15. J. Arfvidsson, L.-E. Harderup, I. Samuelson, Fukthandbok, 4, 53 (2017)

16. Svenskt Trä, [Accessed: 10-Jan-2020].

17. A. Laukkarinen, J. Vinha, Energy Procedia, 132, 711-716 (2017) 